\title{
Clinical Stages in Patients with Primary and Subsequent Cancers Based on the Czech Cancer Registry 1976-2005
}

\author{
Edvard Geryk, ${ }^{1}$ Radim Štampach, ${ }^{2}$ Petr Dítě, ${ }^{3}$ Jiří Kozel, ${ }^{2}$ \\ Teodor Horváth, ${ }^{4}$ and Petr Kubíček ${ }^{2}$ \\ ${ }^{1}$ Department of Science and Research, University Hospital Brno, Jihlavska 20, 62500 Brno, Czech Republic \\ ${ }^{2}$ Laboratory on Geoinformatics and Cartography, Department of Geography, Faculty of Science, Masaryk University, Kotlarska 2, \\ 61137 Brno, Czech Republic \\ ${ }^{3}$ Department of Internal Medicine, University Hospital Brno, Pekarska 53, 60200 Brno, Czech Republic \\ ${ }^{4}$ Department of Surgery, University Hospital Brno, Jihlavska 20, 62500 Brno, Czech Republic
}

Correspondence should be addressed to Edvard Geryk; egeryk@fnbrno.cz

Received 13 April 2013; Accepted 9 June 2013

Academic Editors: N. Fujimoto, O. Hansen, R. Nahta, K. Sonoda, M. Stracke, and K. van Golen

Copyright ( 2013 Edvard Geryk et al. This is an open access article distributed under the Creative Commons Attribution License, which permits unrestricted use, distribution, and reproduction in any medium, provided the original work is properly cited.

Of 1,486,984 new cancers registered in the Czech Cancer Registry in 1976-2005, 290,312 (19.5\%) were multiple malignant neoplasms (MMNs), of which there were 65,292 primary and 89,796 subsequent cases in men and 59,970 primary and 75,254 subsequent cases in women. The duplicities were higher in women, and the triplicities and others (3-6 MMNs) were higher in men. The most frequent diagnoses were the primary cancers of skin, gastrointestinal and urinary tract, male genital organs, respiratory tract in men, and cancers of skin, breast, female genital organs, and gastrointestinal tract in women. The analysis of the early and advanced clinical stages shows that the number of subsequent advanced stages increased after primary advanced stages. Their time-age-space distributions visualized maps of MMNs in 14 Czech regions. These results support the improvement of algorithms of dispensary care for the early detection of the subsequent neoplasms.

\section{Introduction}

The health status of the Czech population can be seen as very vulnerable, mainly because of the high risk of cancer especially in younger age. This fact is confirmed by data in Globocan 2008 [1]. Cancer diagnoses are registered since 1959. The IARC criteria are used were for their notificationed since May 1976 by criteria of the IARC. The annual surveys of Health Information and Statistics of the Czech Republic [2] confirmed the continued trend of cancer occurrence, observed in the Czech areas from 1905 [3] and continuously described from 1933 [4]. The cancer incidence increased from $24,471(254.4 / 100,000)$ in 1959 over 35,407 (347.5/100,000) in 1977 to $78,846(751.5 / 100,000)$ in 2009 [2]. In view of new diagnostic and treatment modalities, the prevalence of cancers (ICD-10: C00-97, D00-09) increased from 174,311 $(1,682.2 / 100,000)$ in 1989 to $461,545(4,510 / 100,000)$ in 2005. Under the conditions of continuous diagnostics, treatment, medical surveillance, and cancer evidence, the survivors can reach in 2015 nearly 317,000 cases in men (of which $33.2 \%$ in age $35-64$ years) and 434,000 in women (of which $42.6 \%$ in age 35-64 years) [5]. The differences between the numbers of cases and numbers of persons indicated the multiple malignant neoplasms (MMNs). After the preliminary report of their trend [6], this paper is another contribution to this issue.

\section{Methods}

The data of MMNs were based on the number of cancers reported to the Czech Cancer Registry between May 1976 and December 2005 and were verified and anonymised up to October 17, 2007. The percentage of multiple cancers of all diagnoses (ICD-10: C00-97, D00-09, D37-48, i.e. including the skin cancer) in males and females was compared with the number of newly diagnosed cases in the same codes. The primary and subsequent cancers were prepared in contingency tables and analysed by age, time and space distribution, 


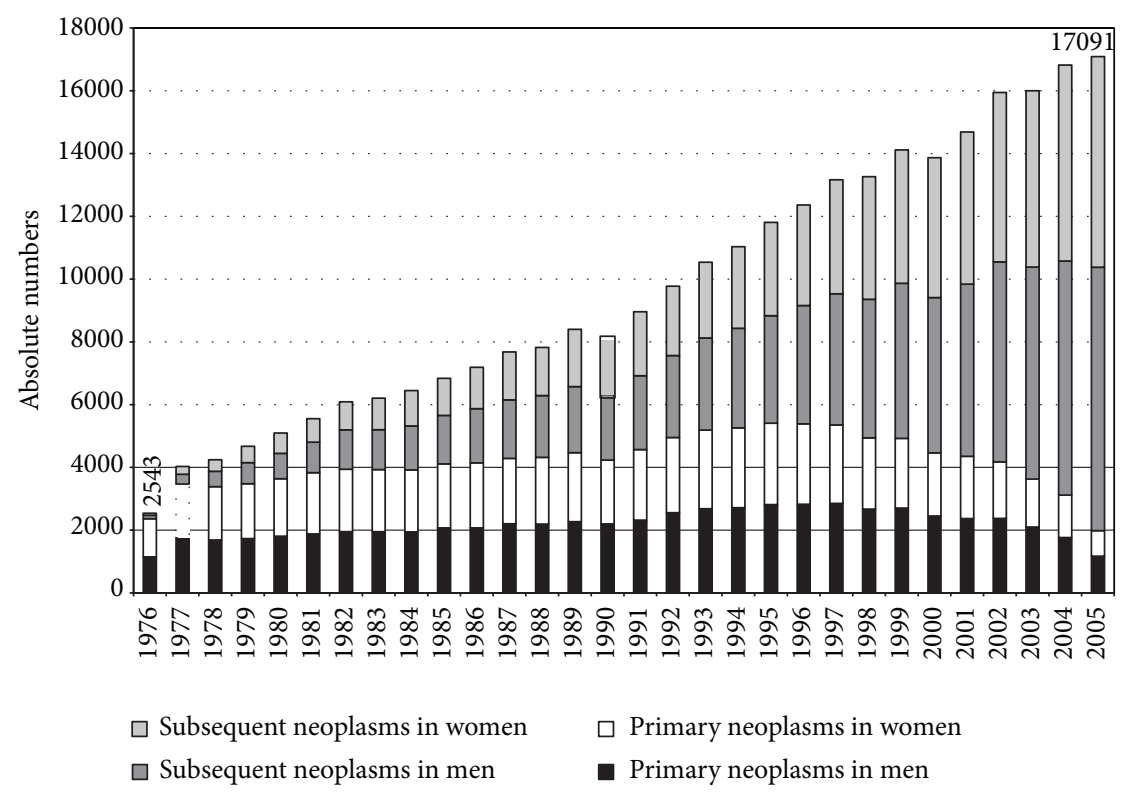

FIGURE 1: Trend of multiple malignant neoplasms in the Czech Republic 1976-2005.

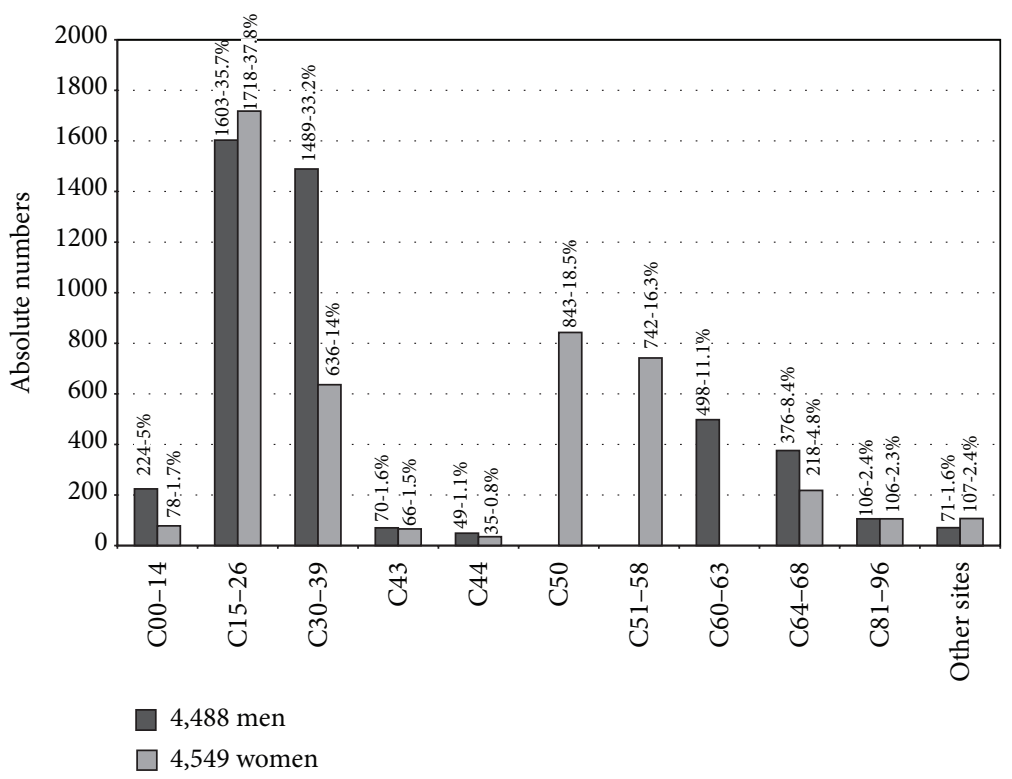

FIGURE 2: Subsequent diagnoses of advanced stages following primary neoplasms of early stages.

and clinical stages of early (ST I, II), advanced (ST III, IV), and unknown cases. Their input data correspond with the classification of diseases at the time of diagnosis and with the level of cancer evidence in 14 Czech regions.

\section{Results}

A total of $1,486,984$ new malignant neoplasms $(50.9 \%$ men, $49.1 \%$ women) were registered in the Czech Cancer Registry between 1976 and 2005. This number includes $1,430,458$ (96.2\%) cancers (C00-97), 42,630 (2.9\%) neoplasms in situ (D00-09), and 13,896 (0.9\%) neoplasms of uncertain behaviour (D37-48). Of all newly registered cancers, there were notified 290,312 (19.5\%) MMNs. In men were diagnosed 65,292 primary and 89,796 subsequent cancers and in women 59,970 primary and 75,254 subsequent cancers. A total of $84 \%$ duplicities were higher in women than $79.6 \%$ in men, while triplicities and others (3-6 MMNs) were in $19.1 \%$ cases of men and $15.4 \%$ of women. In men, there were the most frequent primary cancers of skin $46 \%$, gastrointestinal $13.5 \%$ and urinary tract $9.6 \%$, male genital organs $8.1 \%$ and respiratory tract $7.7 \%$; in women, there were cancers of skin $39.4 \%$, breast $17.3 \%$, female genital organs $14.7 \%$, and gastrointestinal tract $9.8 \%$. The most frequent MMNs were 53,616 primary and 70,119 subsequent cancers of skin as a warning sign for the risk of following neoplasms. The most frequent subsequent 


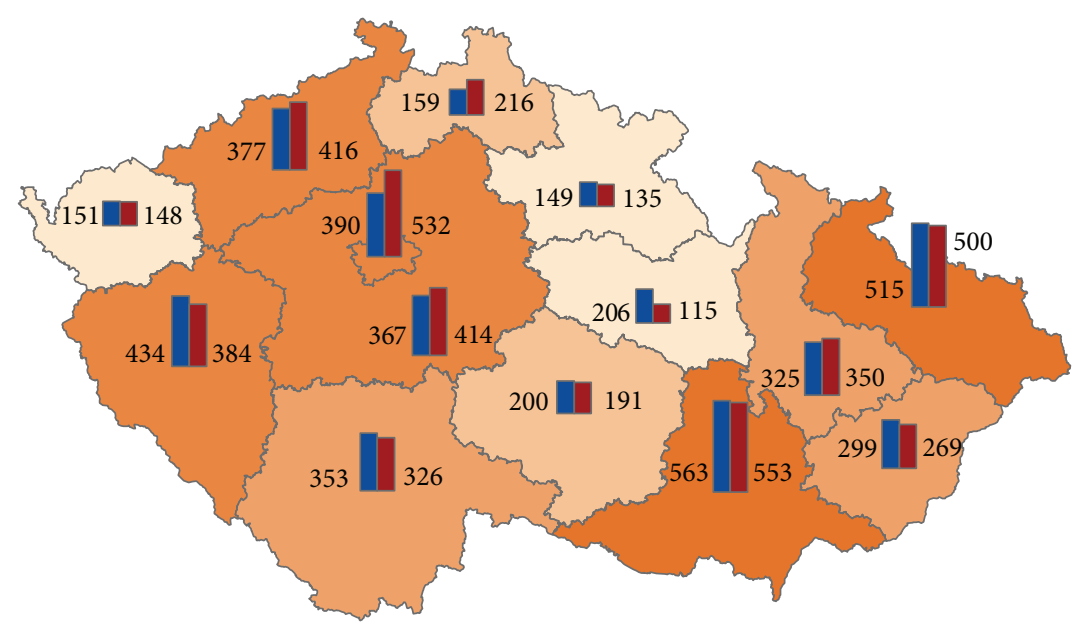

Number of cases in advanced stages:

Number of cases in males and females:

$\begin{array}{llllll}284 & 350 & 500 & 700 & 1000 & 1116\end{array}$

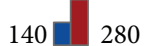

Males Females

FIGURE 3: Advanced clinical stages of subsequent neoplasms after early clinical stages of primary neoplasms in regions of the Czech Republic in 4,488 males and 4,549 females in 1976-2005.

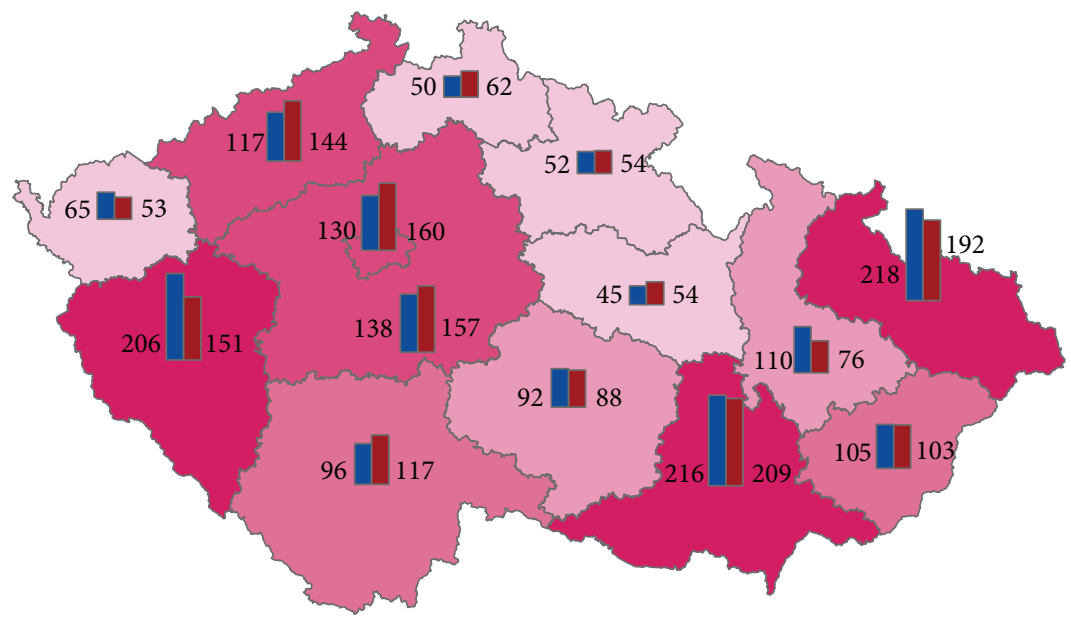

Number of cases in advanced stages:

99 $\begin{array}{lllll}150 & 200 \quad 250 \quad 320 \quad 425\end{array}$
Number of cases in males and females:

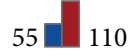

Males Females

FIGURE 4: Advanced clinical stages of subsequent neoplasms after advanced clinical stages of primary neoplasms in regions of the Czech Republic in 1,640 males and 1,620 females in 1976-2005.

diagnoses following primary cases were 26,790 cancers of gastrointestinal tract (54.6\% men, $45.4 \%), 12,801$ of respiratory tract (76.9\% men, $23.1 \%$ women), 10,704 of urinary tract ( $66.6 \%$ men, $33.4 \%$ women), 9,394 of breast ( $0.9 \%$ men, $99.1 \%$ women), 5,284 of lymphoid and haematopoietic tissue $(54.3 \%$ men, $45.7 \%$ women), and 6,804 of male and 9,309 of female genital organs (Table 1).

The yearly number of MMNs increased from 2,543 cases in 1976 to 17,091 in 2005, of which the primary cancers increased from 2,365 in 1976 to 5,411 in 1995 and then decreased to 1,983 in 2005 , while the subsequent cancers increased from 178 in 1976 to 15,108 in 2005 (Figure 1). The predominance of unknown stages in both sexes over other stages lasted until 1994; from the next years their number decreased especially in the early stages of primary cancers. The percentage occurrence of stage IV was permanently higher in men than in women.

Let us see the situation in age groups. The values of the primary cancers in age group up to 49 years are $8.3 \%$ cases in men and $15.7 \%$ in women, in group $50-69$ years $52.4 \%$ in 


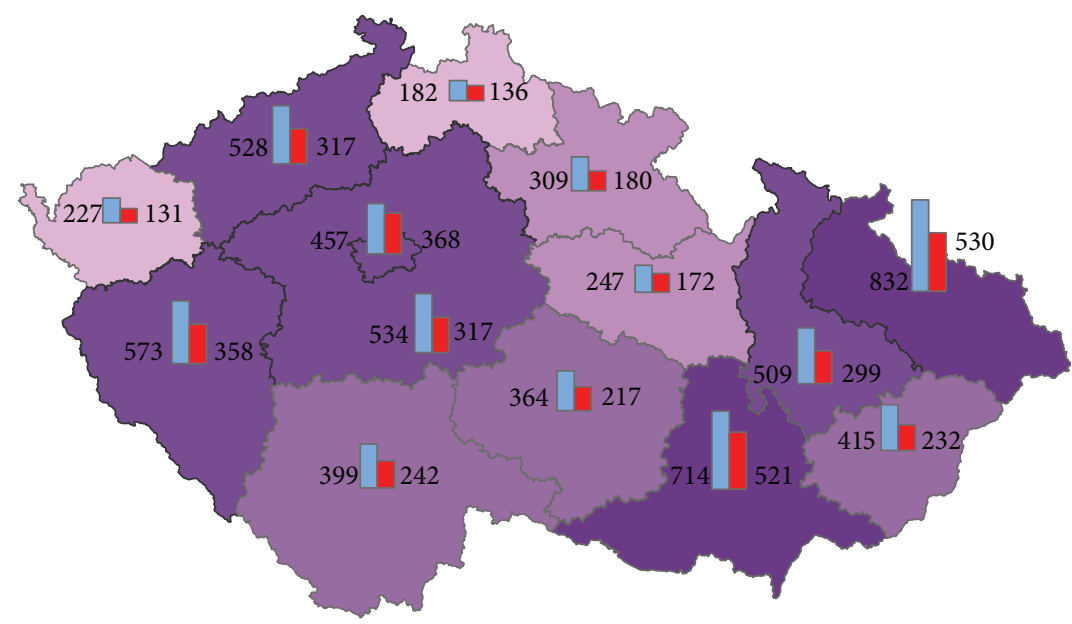

Number of cases in advanced stages:

Number of cases in males and females:

$\begin{array}{llllll}318 & 400 & 500 & 700 & 1100 & 1362\end{array}$

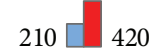

Males Females

FIGURE 5: Advanced clinical stages of subsequent neoplasms after unknown clinical stages of primary neoplasms in regions of the Czech Republic in 6,290 males and 4,020 females in 1976-2005.
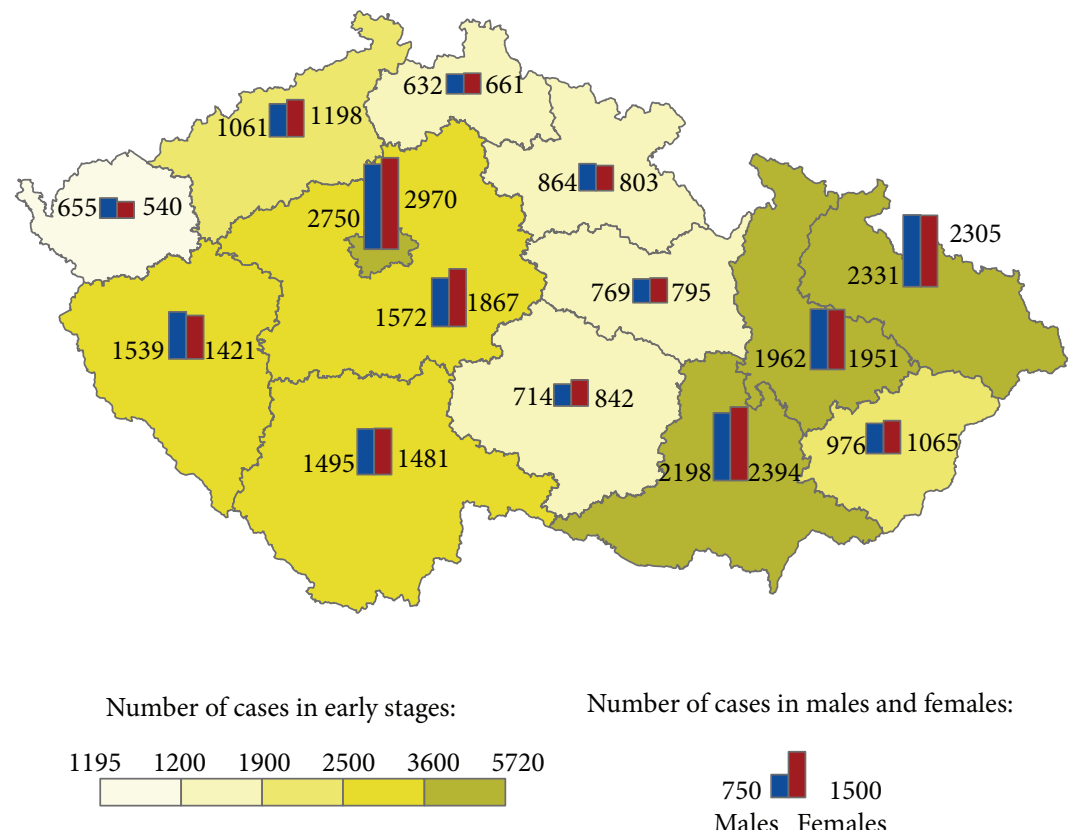

Number of cases in males and females:

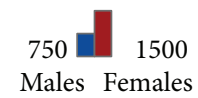

Figure 6: Early clinical stages of subsequent neoplasms after early clinical stages of primary neoplasms in regions of the Czech Republic in 19,504 males and 20,307 females in 1976-2005.

men and $47.8 \%$ in women, in group $70-79$ years $31.3 \%$ in men and $26.7 \%$ in women, and in group over 80 years $8 \%$ in men and $9.8 \%$ in women. After the exclusion of unknown stages, the numbers of early stages were higher in men in group of $70-79$ years, in women in group up to 49 years, and in group over 80 years. The numbers of advanced stages were higher in men in group of 50-79 years.

Of the total 65,292 primary cancers in men, were diagnosed $24,263(37.1 \%)$ cases of early stages (of which $28.2 \%$
ST I) and 6,051 (9.3\%) cases of advanced stages (of which $4.2 \%$ ST IV); the unknown stages featured 34,978 (53.6\%) cases. Of the total 59,970 primary cancers in women were diagnosed $27,922(46.6 \%)$ cases of early stages (of which $32.6 \%$ ST I), 5,707 (9.5\%) cases of advanced stages (of which $3.2 \%$ ST IV); the unknown stages featured 26,341 (43.9\%) cases. The specific position presents 22,607 subsequent cancers of advanced stages (ST III, IV), of which 6,172 cases (i.e. $12.4 \%$ of 49,717 ) followed primary ST I, 2,865 cases (i.e. $17.3 \%$ 


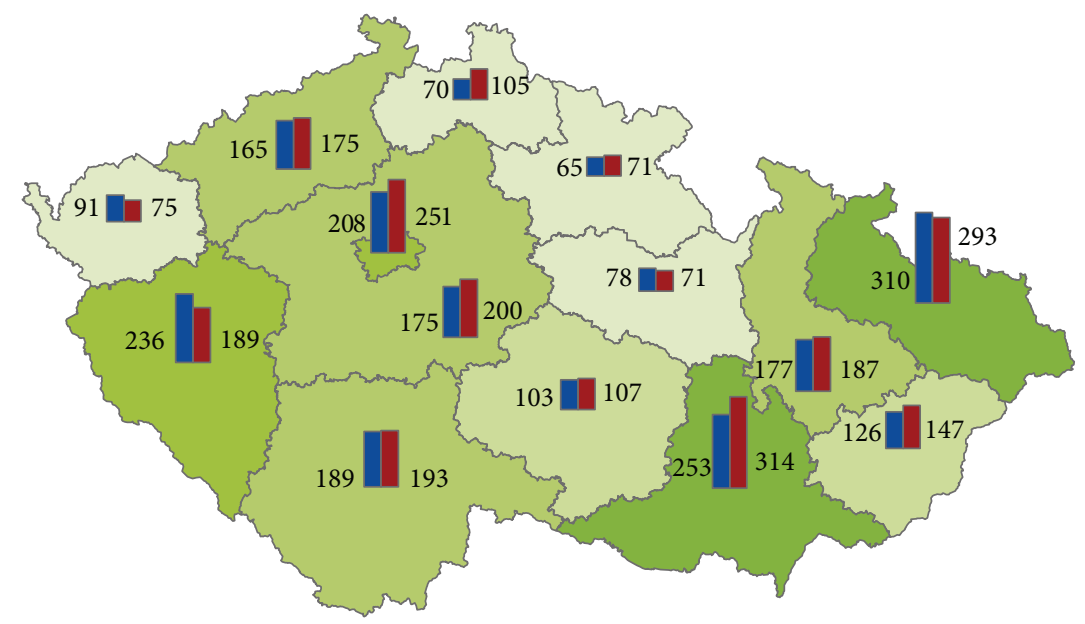

Number of cases in early stages:

Number of cases in males and females:
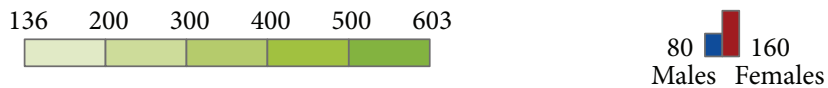

FIGURE 7: Early clinical stages of subsequent neoplasms after advanced clinical stages of primary neoplasms in regions of the Czech Republic in 2,246 males and 2,378 females in 1976-2005.

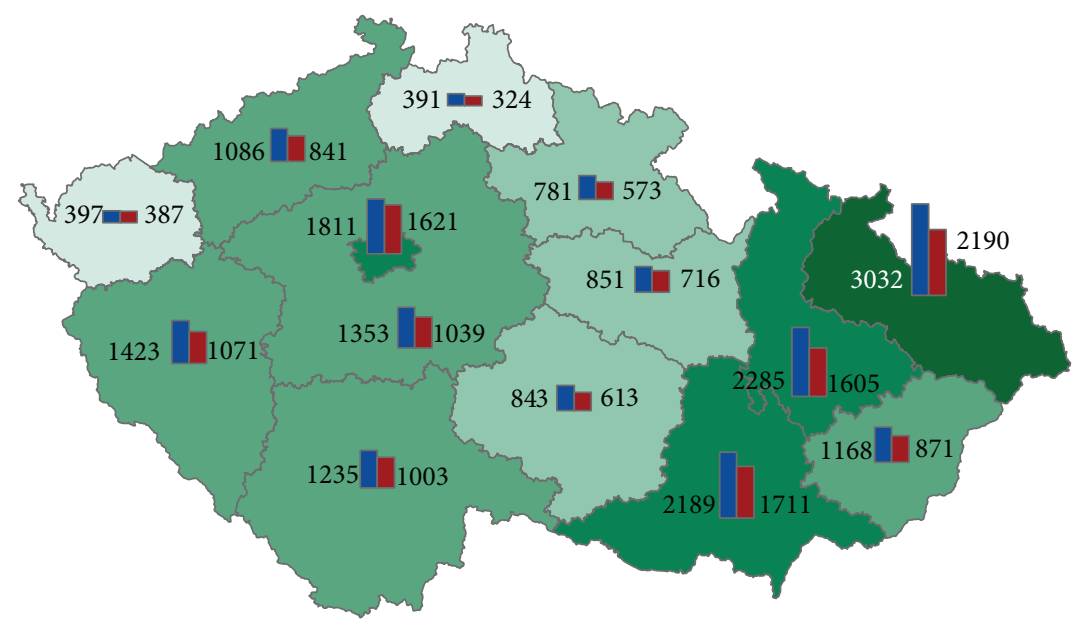

Number of cases in early stages:

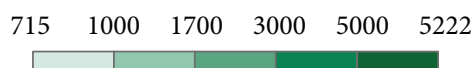

Number of cases in males and females:

$$
\begin{gathered}
750 \\
\text { Males Females }
\end{gathered}
$$

FIGURE 8: Early clinical stages of subsequent neoplasms after unknown clinical stages of primary neoplasms in regions of the Czech Republic in 18,845 males and 14,565 females in 1976-2005.

of 16,533$)$ followed primary ST II, 1,905 cases (i.e. $24.1 \%$ of 7,890 ) followed primary ST III, 1,355 cases (i.e. $27.2 \%$ of 4,976 ) followed primary ST IV, and 10,310 cases (i.e. $12 \%$ of 85,934 ) followed primary unknown stages (Table 2). The number of subsequent advanced stages increased with the advanced stage of primary disease.

The geographical distribution of MMNs by stages during 1976-2005 shows relevant maps (Figures 3, 4, 5, 6, 7,
$8,9,10$, and 11). The most frequent values of primarysubsequent cancers of 14 regions reached the population of Northern Moravia-primary $12.7 \%$ and subsequent $13.7 \%$, Prague-primary $11.8 \%$ and subsequent $11.8 \%$, and Southern Moravia-primary $11.8 \%$ and subsequent $11.7 \%$. The distribution of advanced stages presents two percentage values.

The comparison with total advanced stages in subsequent cancers was higher in regions nos. 11 (12.7\%), 14 (12.1\%), 


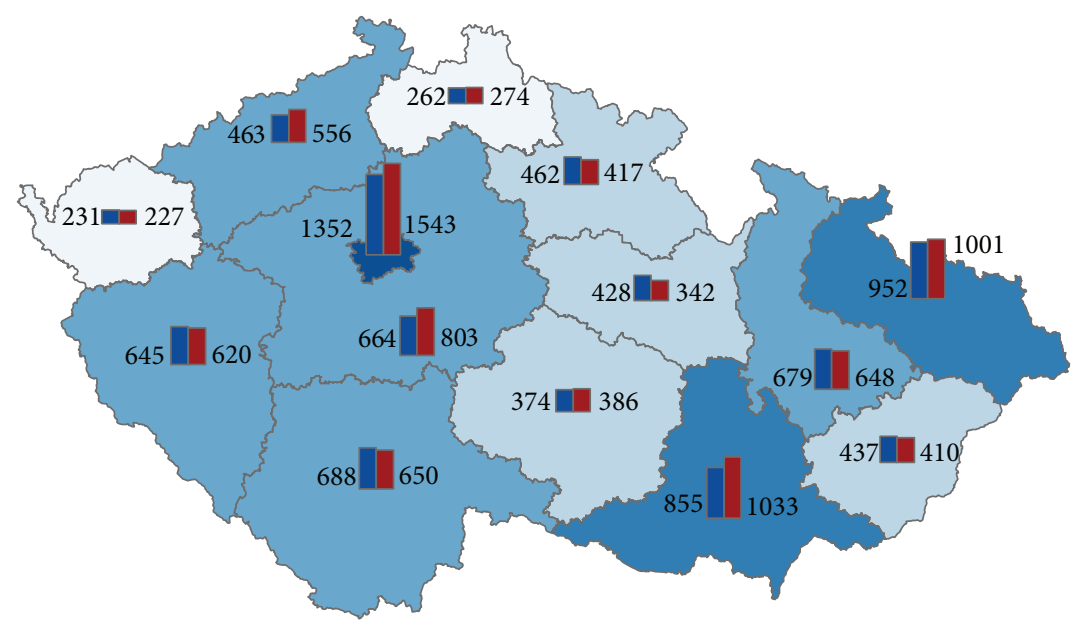

Number of cases in unknown stages:

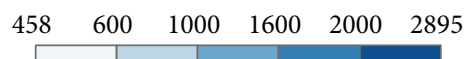

Number of cases in males and females:

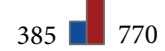

Males Females

FIGURE 9: Unknown clinical stages of subsequent neoplasms after early clinical stages of primary neoplasms in regions of the Czech Republic in 8,492 males and 8,910 females in 1976-2005.

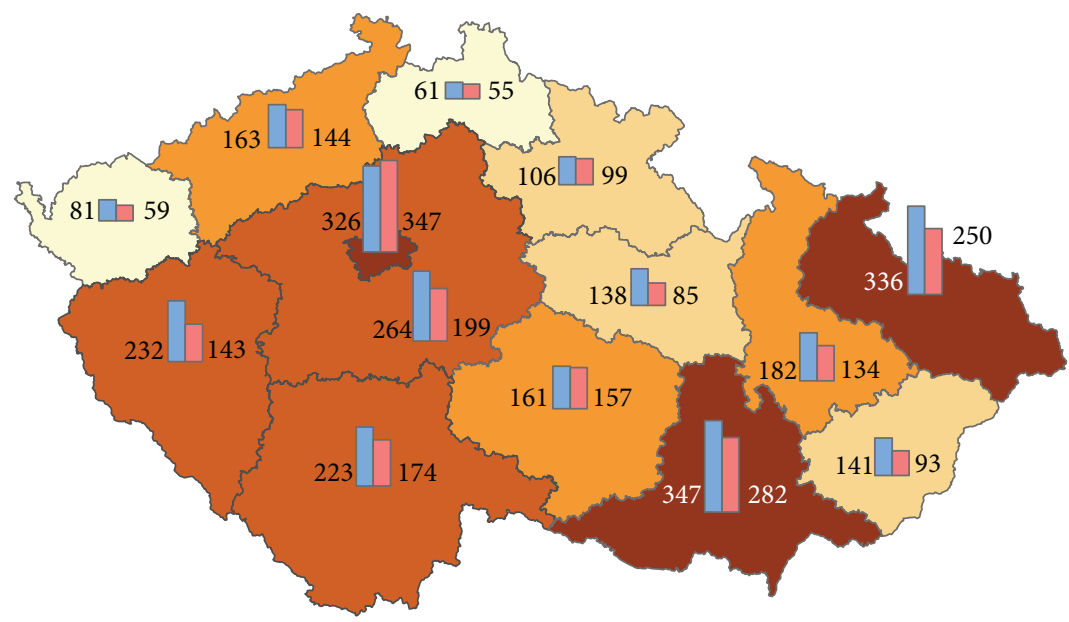

Number of cases in unknown stages:

Number of cases in males and females:

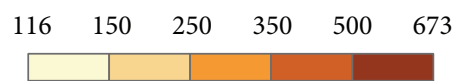

$$
85 \square 170
$$

Males Females

FIGURE 10: Unknown clinical stages of subsequent neoplasms after advanced clinical stages of primary neoplasms in regions of the Czech Republic in 2,761 males and 2,221 females in 1976-2005.

$4(9.7 \%)$, and $1(9.5 \%)$, while the comparison with all subsequent cancers in the relevant region was higher in regions nos. 6 (15.4\%), 7 (14.7\%), 4 (13.6\%), 5 (13.6\%) and $13(12.4 \%)$ as an indicator of late diagnosis of subsequent cancer during medical surveillance (Table 3). Of the various comparisons are presented 9,037 advanced stages of subsequent cancers following primary neoplasms with higher value of 1603 (35.7\%) gastrointestinal tract in men and 1718 (37.8\%) in women, $1489(33.2 \%)$ respiratory tract in men and $636(14 \%)$ in women, $843(18.5 \%)$ breast, $742(16.3 \%)$, female genital organs, 498 (11.1\%) male female genital organs, and $376(8.4 \%)$ urinary tract in men and $218(4.8 \%)$ in women (Figure 2).

Up to October 17, 2007, there were registered of 65,292 primary cancers of men 18,887 (28.9\%) surviving and 46,405 (71.1\%) deaths, of 59,970 primary cancers of women 22,274 (37.1\%) surviving and 37,696 (62.9\%) deaths. Of total surviving cases were $54.7 \%$ early stages in men and $58 \%$ in women, $5 \%$ advanced stages in men and $5.2 \%$ in women; the unknown 


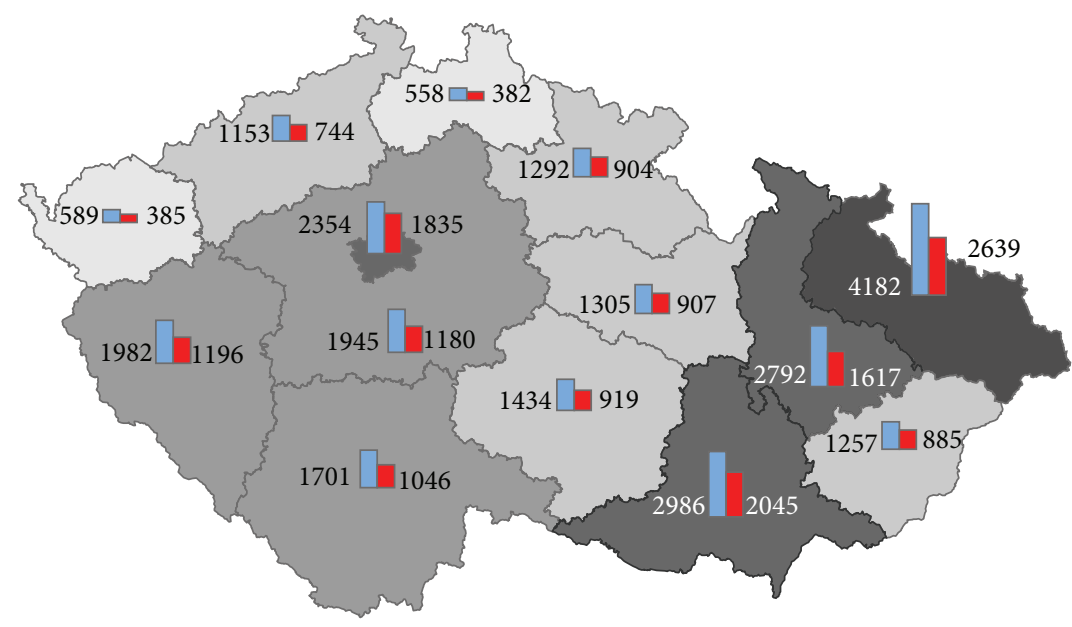

Number of cases in unknown stages: $\quad$ Number of cases in males and females:

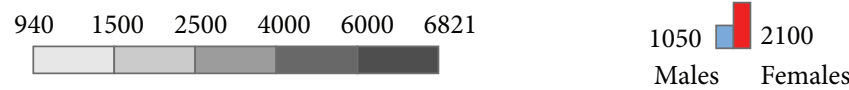

FIGURE 11: Unknown clinical stages of subsequent neoplasms after unknown clinical stages of primary neoplasms in regions of the Czech Republic in 25,530 males and 16,684 females in 1976-2005.

TABLE 1: New cancers and multiple malignant cases based on the Czech Cancer Registry 1976-2005 (up to October 17, 2007, data in 1976 from May).

\begin{tabular}{|c|c|c|c|c|c|c|c|c|c|}
\hline \multirow{2}{*}{ Malignant neoplasm } & \multirow{2}{*}{ ICD-10 } & \multicolumn{4}{|c|}{ Men } & \multicolumn{4}{|c|}{ Women } \\
\hline & & New MN & $\%(a)$ & MMNs & $\%(b)$ & New MN & $\%(a)$ & MMNs & $\%(b)$ \\
\hline Oral cavity, pharynx & $\mathrm{C} 00-14$ & 20673 & 2,8 & 2070 & 3,2 & 6241 & 0,9 & 540 & 0,9 \\
\hline Gastrointestinal tract & $\mathrm{C} 15-26$ & 193547 & 25,6 & 8862 & 13,6 & 162077 & 22,2 & 5882 & 9,8 \\
\hline Respiratory tract & C30-39 & 162315 & 21,4 & 5093 & 7,7 & 32263 & 4,4 & 887 & 1,5 \\
\hline Bone, articular cartilage & C40-41 & 1765 & 0,2 & 70 & 0,1 & 1320 & 0,2 & 50 & 0,1 \\
\hline Melanoma of skin & $\mathrm{C} 43$ & 14331 & 1,9 & 1626 & 2,5 & 15327 & 2,1 & 1518 & 2,5 \\
\hline Skin & $\mathrm{C} 44$ & 134727 & 17,8 & 30012 & 46 & 129787 & 17,8 & 23604 & 39,4 \\
\hline Mesothelial, soft tissue & $\mathrm{C} 45-49$ & 5489 & 0,7 & 321 & 0,5 & 5177 & 0,7 & 267 & 0,4 \\
\hline Breast & $\mathrm{C} 50$ & 978 & 0,1 & 128 & 0,2 & 118546 & 16,2 & 10352 & 17,3 \\
\hline Female genital organs & C51-58 & 0 & 0 & 0 & 0 & 115912 & 15,9 & 8785 & 14,7 \\
\hline Male genital organs & $\mathrm{C} 60-63$ & 74560 & 9,8 & 5265 & 8,1 & 0 & 0 & 0 & 0 \\
\hline Urinary tract & C64-68 & 67530 & 8,9 & 6278 & 9,6 & 32807 & 4,5 & 2221 & 3,7 \\
\hline Eye, brain, nervous system & $\mathrm{C} 69-72$ & 10734 & 1,4 & 305 & 0,5 & 9130 & 1,3 & 286 & 0,5 \\
\hline Thyroid and other glands & C73-75 & 3248 & 0,4 & 222 & 0,3 & 9357 & 1,3 & 585 & 1 \\
\hline Unspecified sites & $\mathrm{C} 76-80$ & 13539 & 1,8 & 392 & 0,6 & 13951 & 1,9 & 323 & 0,5 \\
\hline Lymphoid, haematol. tissue & C81-96 & 40071 & 5,3 & 2667 & 4,1 & 35056 & 4,8 & 1697 & 2,8 \\
\hline In situ & D00-09 & 7438 & 1 & 1161 & 1,8 & 35192 & 4,8 & 2301 & 3,8 \\
\hline Uncertain behaviour & D37-48 & 6449 & 0,9 & 820 & 1,3 & 7447 & 1 & 672 & 1,1 \\
\hline Total sites & C00-D48 & 757394 & 100 & 65292 & 100 & 729590 & 100 & 59970 & 100 \\
\hline
\end{tabular}

$\%$ (a): relevant diagnosis in percent of all new cancers.

$\%$ (b): relevant diagnosis in percent of all malignant neoplasms.

stages featured $40.3 \%$ in men and $36.9 \%$ in women. Of total deceased cases were $30 \%$ early stages in men and $39.8 \%$ in women, $11 \%$ advanced stages in men and $12.1 \%$ in women; the unknown stages featured $11 \%$ in men and $12.1 \%$ in women.

\section{Discussion}

From ongoing analysis of Cancer Registry database were published the results of the MMNs of breast [7], skin [8], prostate [9], gastrointestinal tract [10], brain [11], lung [12], head and neck [13], testis [14], and penis cancer [15]. We pointed to the current and future relationships of MMNs with ethical and economic burden of the Czech population [16]. We used experiences of more than 50 references, concerning the MMNs. Unfortunately the excellent source which analysed the MMNs of SEER database [17] did not contain data about clinical stages as well as the most of another recent reference [18]. 
TABLE 2: Primary and subsequent neoplasms by clinical stages 19762005 (Source: Czech Cancer Registry, up to October, 2007). Values of subsequent neoplasms in advanced stages are in bold.

\begin{tabular}{|c|c|c|c|c|}
\hline Primary & Subsequent & Total & Men & Women \\
\hline \multirow{5}{*}{ ST I } & ST I & 25936 & 13486 & 12450 \\
\hline & ST II & 5220 & 2429 & 2791 \\
\hline & ST III & 2731 & 1331 & 1400 \\
\hline & ST IV & 3441 & 1893 & 1548 \\
\hline & Unknown & 12389 & 6317 & 6072 \\
\hline Total & & 49717 & 25456 & 24261 \\
\hline \multirow{5}{*}{ ST II } & ST I & 5927 & 2534 & 3393 \\
\hline & ST II & 2728 & 1055 & 1673 \\
\hline & ST III & 1310 & 529 & 781 \\
\hline & ST IV & 1555 & 735 & 820 \\
\hline & Unknown & 5013 & 2175 & 2838 \\
\hline Total & & 16533 & 7028 & 9505 \\
\hline \multirow{5}{*}{ ST III } & ST I & 2163 & 953 & 1210 \\
\hline & ST II & 980 & 389 & 591 \\
\hline & ST III & 951 & 417 & 534 \\
\hline & ST IV & 954 & 473 & 481 \\
\hline & Unknown & 2842 & 1427 & 1415 \\
\hline Total & & 7890 & 3659 & 4231 \\
\hline \multirow{5}{*}{ ST IV } & ST I & 1040 & 644 & 396 \\
\hline & ST II & 441 & 260 & 181 \\
\hline & ST III & 341 & 191 & 150 \\
\hline & ST IV & 1014 & 559 & 455 \\
\hline & Unknown & 2140 & 1334 & 806 \\
\hline Total & & 4976 & 2988 & 1988 \\
\hline \multirow{5}{*}{ Unknown } & ST I & 26757 & 15184 & 11573 \\
\hline & ST II & 6653 & 3661 & 2992 \\
\hline & ST III & 4324 & 2483 & 1841 \\
\hline & ST IV & 5986 & 3807 & 2179 \\
\hline & Unknown & 42214 & 25530 & 16684 \\
\hline Total & & 85934 & 50665 & 35269 \\
\hline Total all sites & & 165050 & 89796 & 75254 \\
\hline
\end{tabular}

Registered new cases of malignant neoplasms contain also other primary subsequent cancer diagnoses, first described by Billroth and von Winiwarer in 1889 [19]. As their possible causes were assessed the previous radiotherapy [20-23] and chemotherapy [24-28], dialysis [29], transplantation [30-32], and genetic predisposition [33,34]. Their relationship for the risk of the MMNs was not statistically significant. Nevertheless, there is an agreement that the mutual coincidence of these causes can promote the occurrence of subsequent cancers with high burden on patients, their families, and oncologists, including the extraordinary difficulty of palliative care in the terminal period.

It can be assumed that the dispensary care can bring except the metastasis also other topographically and histologically different cancers. Their treatment has similar conditions by clinical stages even when the subsequent cancer can change the treatment scheme of the primary disease. 22,607 advanced stages, that is, $13.7 \%$ of all 165,050 subsequent cases during 29 years-is it high or low number? It is important to note that the number of subsequent advanced stages increased with advanced stage of primary disease. These results can contribute to the algorithms of dispensary care
TABLE 3: Advanced stages of subsequent neoplasms by regions 19762005 (Source: Czech Cancer Registry, up to October, 2007). Names of regions were changed to numbers because of anonymization.

\begin{tabular}{lcccccc}
\hline Region ADV-EAR & ADV-ADV & ADV-UNKN & Total & $\%(\mathrm{a})$ & $\%(\mathrm{~b})$ \\
\hline 1 & 922 & 290 & 498 & 1710 & $\mathbf{9 , 5}$ & 8,8 \\
2 & 781 & 295 & 455 & 1531 & 8,5 & 11,6 \\
3 & 679 & 213 & 338 & 1230 & 6,8 & 10,6 \\
4 & 818 & 357 & 564 & 1739 & $\mathbf{9 , 7}$ & $\mathbf{1 3 , 6}$ \\
5 & 299 & 118 & 196 & 613 & 3,4 & $\mathbf{1 3 , 6}$ \\
6 & 793 & 261 & 434 & 1488 & 8,3 & $\mathbf{1 5 , 4}$ \\
7 & 375 & 112 & 186 & 673 & 3,7 & $\mathbf{1 4 , 7}$ \\
8 & 284 & 106 & 232 & 622 & 3,5 & 8,5 \\
9 & 321 & 99 & 217 & 637 & 3,5 & 8,7 \\
10 & 391 & 180 & 309 & 880 & 4,9 & 11,3 \\
11 & 1116 & 425 & 737 & 2278 & $\mathbf{1 2 , 7}$ & 11,8 \\
12 & 675 & 186 & 409 & 1270 & 7,1 & 8 \\
13 & 568 & 208 & 337 & 1113 & 6,2 & $\mathbf{1 2 , 4}$ \\
14 & 1015 & 410 & 748 & 2173 & $\mathbf{1 2 , 1}$ & 9,6 \\
\hline
\end{tabular}

ADV-EAR: advanced stages of subsequent cancers following early stages of primary cancers.

ADV-ADV: advanced stages of subsequent cancers following advanced stages of primary cancers.

ADV-UNKN: advanced stages of subsequent cancers following unknown stages of primary cancers.

$\%$ (a): percent of total advanced stages in subsequent cancers.

$\%$ (b): percent of subsequent cancers in the relevant region.

and early detection of the subsequent neoplasms. During 1977-2005, nearly every fifth cancer disease of the Czech population was associated with the occurrence of histologically different neoplasms.

The presented maps of MMNs by clinical stages are an example of using spatial analysis in our epidemiological research. Spatial epidemiology is the study of the geographical variation in disease risk, incidence, or prevalence [35]. As a growing field of research, spatial epidemiology provides new insights into multiple cancers as it pertains also to the management of permanent medical surveillance in cancer patients [36] and prevention in the health population by modern visualization [37].

\section{Conclusion}

Over 29 years, nearly one in five cancers registered in the Czech population was associated with additional cancer. A total of 165,050 subsequent neoplasms $13.7 \%$ were diagnosed in the advanced stage. The results suggest that information about multiple neoplasms and their clinical stages is necessary as a part of annual statistical cancer report. The most of subsequent advanced stages can be prevented by the therapeutic guidelines.

\section{Authors' Contribution}

Edvard Geryk contributed in the analysis of input data and drafting of the paper, Radim Štampach was involved in the preparation of maps, Petr Dítě supervised the research 
design and execution of analysis, Jiří Kozel contributed in preparation of input anonymous data from source database, Teodor Horváth checked the codes of clinical stages, and Petr Kubíček supervised the maps and contributed in final draft. All authors read and approved the final version of the paper and declare that it is not under simultaneous consideration by any other publication.

\section{Conflict of Interests}

The authors declare that they have no conflict interests.

\section{Acknowledgments}

The source of cancer numbers was the database of Czech Cancer Registry which presented comprehensive information from May 1976 to October 2007 by notification of the Institute of Health Information and Statistics of the Czech Republic in Prague, and the authors wish to thank Mrs. Eliška Vanková for her specifying information of cancer codes.

\section{References}

[1] IARC, “Globocan,” Lyon, France, IARC, 2008, http://globocan. iarc.fr/.

[2] IHIS, Cancer incidence in the Czech Republic. Health statistics, editorial series, http://www.uzis.com/.

[3] "Twenty-five years of the Czech Association for combat and exploration of malignant tumors in Prague," Prague, Czech Republic, 1930.

[4] J. Weiss, "Contribution to the statistics of the cancer increasing," Practical Medicine, vol. 22, article 617, 1933.

[5] M. Konečný, E. Geryk, P. Kubíček et al., Cancer Prevalence in the Czech Republic, 1989-2005-2015, vol. 69, Masaryk University, Brno, Czech Republic, 2008.

[6] E. Geryk, P. Dítě, J. Kozel et al., "Cancer multiplicites in the Czech population,” Casopís Lékařu Českých, vol. 149, no. 4, pp. 178-183, 2010 (Czech).

[7] E. Geryk, M. Bendová, and J. Kozel, "Breast cancer and subsequent primary malignant neoplasms in the Czech Republic 1976-2005," Oncology, vol. 3, no. 1, pp. 54-61, 2009 (Czech).

[8] E. Geryk, P. Dítě, L. Sedláková et al., "Trends of multiple non-melanoma skin cancers in a view of their epidemiology," Practice Dermatology, vol. 4, no. 1, pp. 5-9, 2010 (Czech).

[9] E. Geryk, P. Dítě, J. Kozel et al., "Other primary neoplasms in patients with prostate cancer in comparison of its incidence, mortality and prevalence," Oncology, vol. 4, no. 2, pp. 89-93, 2010 (Czech).

[10] P. Dítě and E. Geryk, "Trends of primary and subsequent cancers of the gastrointestinal tract in the czech population, 1976-2005," Digestive Diseases, vol. 28, no. 4-5, pp. 657-669, 2010.

[11] E. Geryk, J. Kozel, R. Štampach et al., "Multiple cancers of nervous system and other primary neoplasms," Oncology, vol. 5, no. 3, pp. 175-180, 2011 (Czech).

[12] T. Horvath, E. Geryk, J. Kozel et al., "Lung cancer in multiple malignant neoplasms," in Proceedings of the 3rd Lung Cancer Conference, Geneva, Switzerland, 2012.
[13] E. Geryk, J. Kozel, T. Horváth et al., "Patients with multiple cancers of head and neck," Oncology, vol. 6, no. 5, pp. 260-265, 2012 (Czech).

[14] E. Geryk, J. Kozel, D. Pacík, R. Štampach, and T. Horváth, "Multiple cancers of testis," Practice Urology, vol. 14, no. 1, pp. 34-38, 2013 (Czech).

[15] E. Geryk, D. Pacik, J. Kozel et al., "Penile cancers associated with occurrence of other neoplasms," Urology Letters, vol. 10, no. 4, pp. 1-6, 2012 (Czech).

[16] E. Geryk, P. Koška, P. Dítě et al., "Cancers, health and economy: parts of Pandoras box?” Oncology, vol. 7, no. 1, pp. 314-320, 2013 (Czech).

[17] R. E. Curtis, D. M. Freedman, E. Ron et al., New Malignancies Among Cancer Survivors: SEER Cancer Registries 1973-2000, National Cancer Institute, Bethesda, Md, USA, 2006.

[18] ACS, "Multiple primary cancers," in Cancer Facts and Figures 2009, pp. 24-41, American Cancer Society, Atlanta, Ga, USA, 2009.

[19] T. Billroth and A. von Winiwarer, Die Allgemeine Chirurgische Patologie Und Therapie, G. Reimer, Berlin, Germany, 1889.

[20] J. M. Holland, A. Arsanjani, B. J. Liem, S. Christopher Hoffelt, J. I. Cohen, and K. R. Stevens, "Second malignancies in early stage laryngeal carcinoma patients treated with radiotherapy," Journal of Laryngology and Otology, vol. 116, no. 3, pp. 190-193, 2002.

[21] N. N. Baxter, J. E. Tepper, S. B. Durham, D. A. Rothenberger, and B. A. Virnig, "Increased risk of rectal cancer after prostate radiation: a population-based study," Gastroenterology, vol. 128, no. 4, pp. 819-824, 2005.

[22] M. Clarke, R. Collins, S. Darby et al., "Effects of radiotherapy and of differences in the extent of surgery for early breast cancer on local recurrence and 15-year survival: an overview of the randomised trials," The Lancet, vol. 366, no. 9503, pp. 20872106, 2005.

[23] C. Rubino, A. Shamsaldin, M. G. Lê et al., "Radiation dose and risk of soft tissue and bone sarcoma after breast cancer treatment," Breast Cancer Research and Treatment, vol. 89, no. 3, pp. 277-288, 2005.

[24] P. Valagussa, A. Moliterni, M. Terenziani, M. Zambetti, and G. Bonadonna, "Second malignancies following CMF-based adjuvant chemotherapy in resectable breast cancer," Annals of Oncology, vol. 5, no. 9, pp. 803-808, 1994.

[25] J. M. Kaldor, N. E. Day, B. Kittelmann et al., "Bladder tumours following chemotherapy and radiotherapy for ovarian cancer: a case-control study," International Journal of Cancer, vol. 63, no. 1, pp. 1-6, 1995.

[26] L. B. Travis, M. Gospodarowicz, R. E. Curtis et al., "Lung cancer following chemotherapy and radiotherapy for Hodgkin's disease," Journal of the National Cancer Institute, vol. 94, no. 3, pp. 182-192, 2002.

[27] R. E. Curtis, D. M. Freedman, M. E. Sherman, and J. F. Fraumeni Jr., "Risk of malignant mixed mullerian tumors after tamoxifen therapy for breast cancer," Journal of the National Cancer Institute, vol. 96, no. 1, pp. 70-74, 2004.

[28] A. J. Swerdlow, M. E. Jones, D. H. Brewster et al., “Tamoxifen treatment for breast cancer and risk of endometrial cancer: a case-control study," Journal of the National Cancer Institute, vol. 97, no. 5, pp. 375-384, 2005.

[29] C. K. Fairley, A. G. R. Sheil, J. J. McNeil et al., "The risk of anogenital malignancies in dialysis and transplant patients," Clinical Nephrology, vol. 41, no. 2, pp. 101-105, 1994. 
[30] S. A. Birkeland, H. H. Storm, L. U. Lamm et al., "Cancer risk after renal transplantation in the nordic countries, 1964-1986," International Journal of Cancer, vol. 60, no. 2, pp. 183-189, 1995.

[31] R. E. Curtis, P. A. Rowlings, H. J. Deeg et al., "Solid cancers after bone marrow transplantation," The New England Journal of Medicine, vol. 336, no. 13, pp. 897-904, 1997.

[32] S. Euvrard, J. Kanitakis, and A. Claudy, "Skin cancers after organ transplantation," The New England Journal of Medicine, vol. 348, no. 17, pp. 1681-1691, 2003.

[33] T. Kirchhoff, N. D. Kauff, N. Mitra et al., "BRCA mutations and risk of prostate cancer in Ashkenazi jews," Clinical Cancer Research, vol. 10, no. 9, pp. 2918-2921, 2004.

[34] H. D. Nelson, L. H. Huffman, R. Fu, and E. L. Harris, "Genetic risk assessment and BRCA mutation testing for breast and ovarian cancer susceptibility: systematic evidence review for the U.S. Preventive Services Task Force," Annals of Internal Medicine, vol. 143, no. 5, pp. 326-379, 2005.

[35] R. S. Ostfeld, G. E. Glass, and F. Keesing, "Spatial epidemiology: an emerging (or re-emerging) discipline," Trends in Ecology and Evolution, vol. 20, no. 6, pp. 328-336, 2005.

[36] M. Konečný and W. Reinhardt, "Early warning and disaster management: the importance of geographic information," International Journal of Digital Earth, vol. 3, no. 3, pp. 217-220, 2010.

[37] R. Štampach, K. Konečný et al., "Dynamic cartographic methods for visualization of health statistics," in Cartography in Central and Eastern Europe, pp. 431-442, Springer, Berlin, Germany, 2010. 


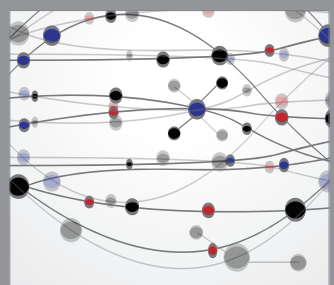

The Scientific World Journal
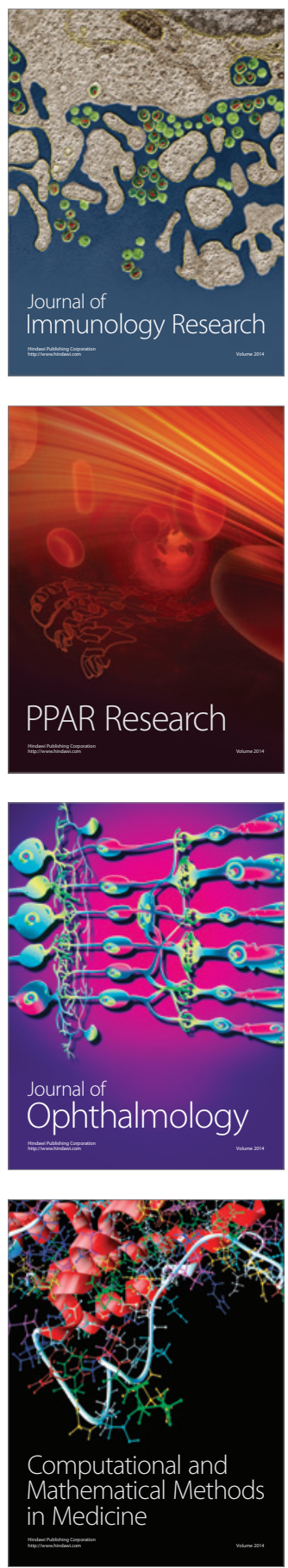

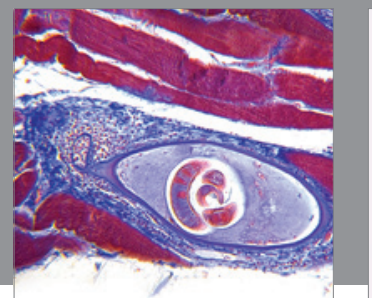

Gastroenterology

Research and Practice
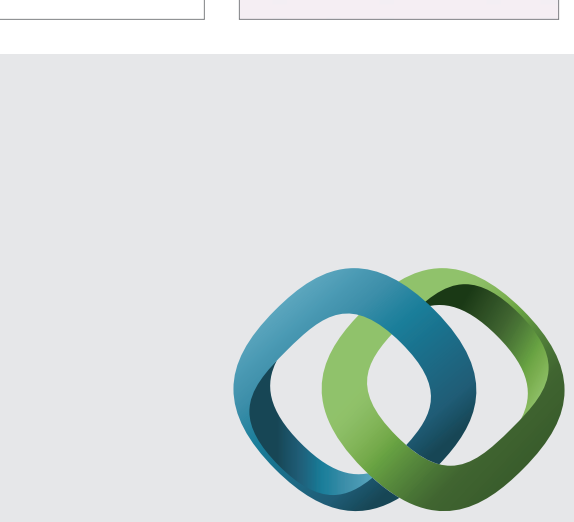

\section{Hindawi}

Submit your manuscripts at

http://www.hindawi.com
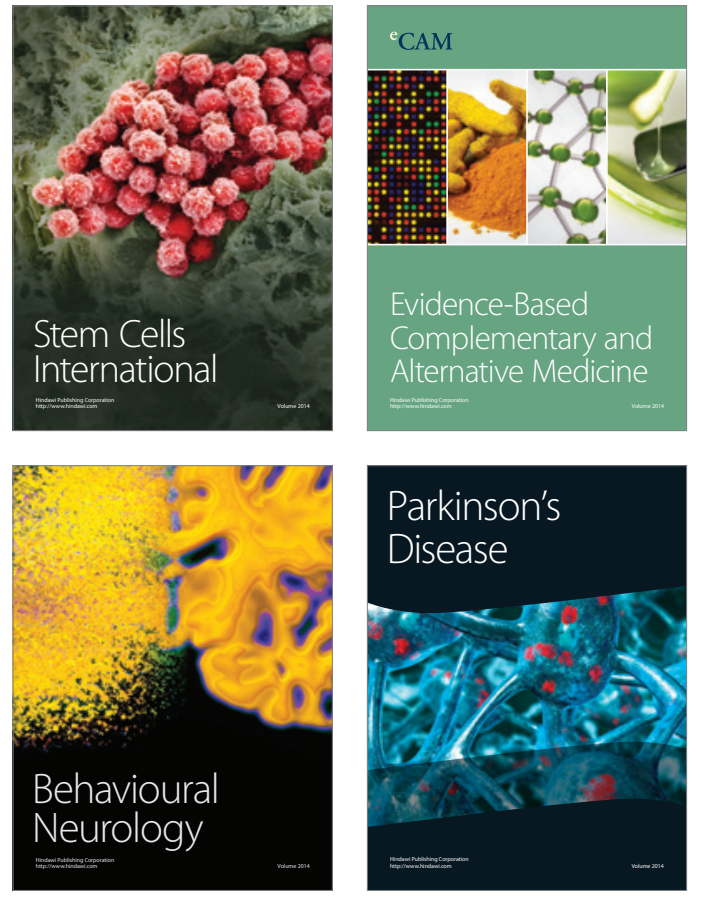
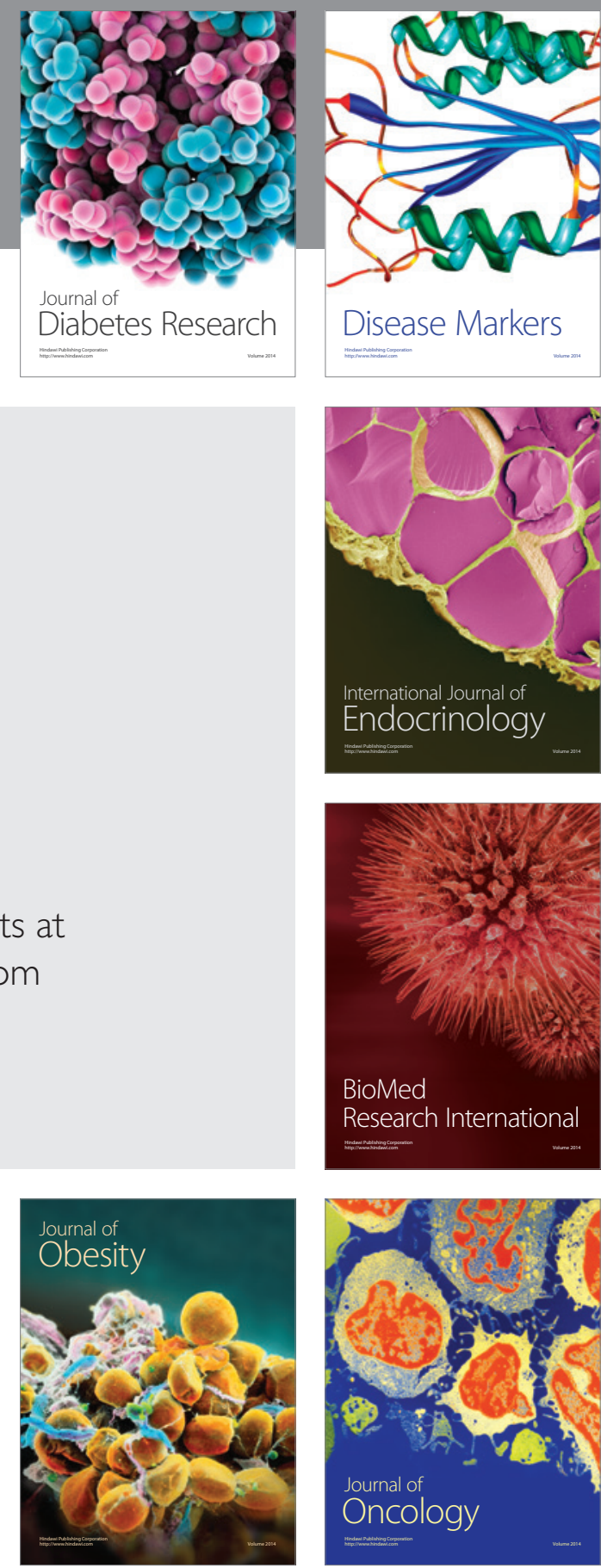

Disease Markers
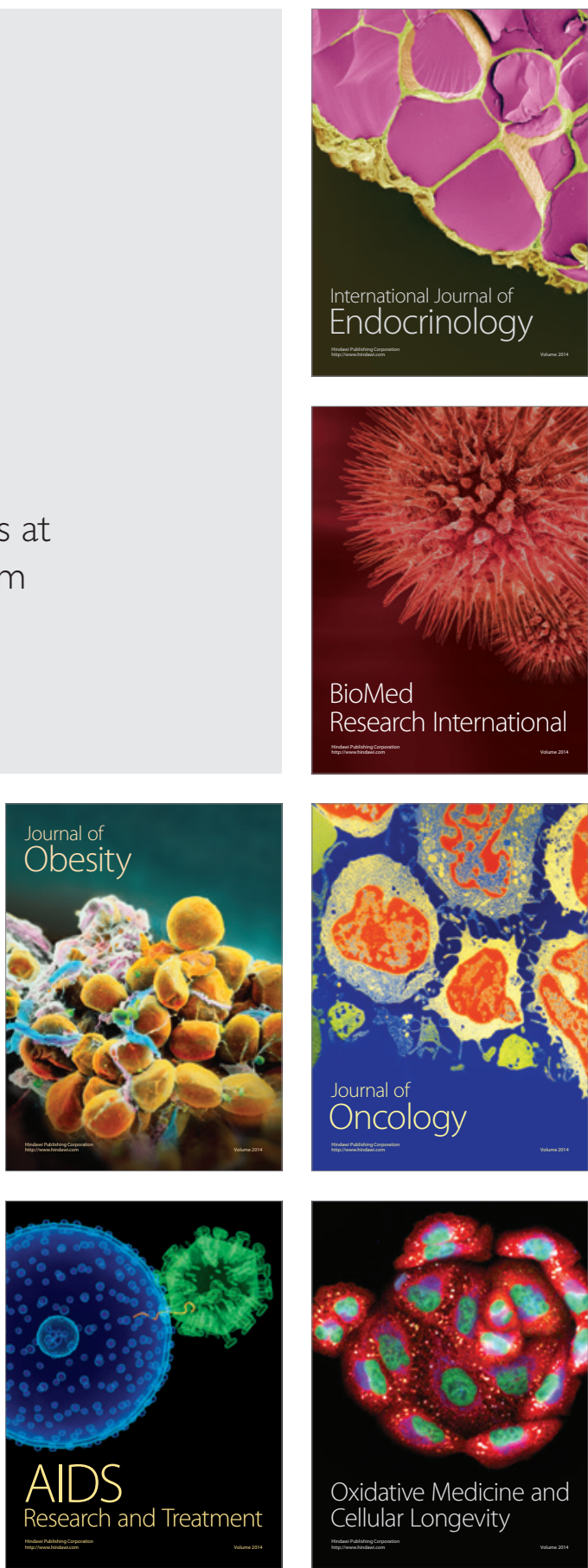